\title{
Self-Assembled Peptide Nanofibers Display Natural Antimicrobial Peptides to Selectively Kill Bacteria without Compromising Cytocompatibility
}

Weike Chen,${ }^{\dagger}$ Su Yang, ${ }^{\dagger}$ Shuxin Li, ${ }^{\ddagger}$ John C. Lang, ${ }^{\dagger}$ Chuanbin Mao,, Peter Kroll, ${ }^{\dagger}$ Liping Tang,, He Dong* ${ }^{\dagger}$

${ }^{\dagger}$ Department of Chemistry \& Biochemistry, The University of Texas at Arlington, Arlington, TX, USA

*Department of Bioengineering, The University of Texas at Arlington, Arlington, TX, USA

$\S$ Department of Chemistry and Biochemistry, Stephenson Life Sciences Research Center, University of Oklahoma, Norman, OK, USA

E-mail: he.dong@uta.edu 


\section{Experimental section}

\section{Synthesis and purification of peptides}

Peptides were synthesized on a Prelude ${ }^{\circledR}$ peptide synthesizer using standard FMOC-solid phase peptide synthesis procedures. Fmoc groups were deprotected in $20 \%(\mathrm{~V} / \mathrm{V})$ piperidine in N, Ndimethylformamide (DMF) for 5 min and repeated 2 times. HBTU was used as the coupling reagent and reacted with Fmoc-protected amino acids in the presence of DIPEA with a molar ratio of 1:1:2.5 (amino acid: HBTU: DIPEA). After the completion of the synthesis, the Nterminus of the peptides were acetylated in the mixed solvents of acetic anhydride and DIPEA in DMF. A mixture of trifluoroacetic acid (TFA) / triisopropanolsilane (TIS) / $\mathrm{H}_{2} \mathrm{O}$ (95/2.5/2.5 by volume) was used to cleavage the acetylated peptides from resin for 3 hours. The cleavage solution was collected through filtration and the wash of neat TFA. TFA solution was evaporated under air flow. The residual peptide solution was precipitated in cold diethyl ether, followed by centrifugation and washing with cold diethyl ether for three times. The crude peptide was dried under vacuum overnight for HPLC purification. The peptide was purified using a preparative reversed phase C4 column with a linear gradient of water/acetonitrile containing $0.05 \%$ TFA. Elution was monitored at $230 \mathrm{~nm}$ and $280 \mathrm{~nm}$. Rhodamine terminated peptides were synthesized as follows. After final deprotection of the peptide, the N-terminus was coupled with 4 equivalents of 5(6)-carboxy-tetramethyl-rhodamine using a combination of 4 equivalents of HCTU and 8 equivalents of DIPEA in DMF. The reaction mixture was stirred overnight. The completion of the coupling reaction was confirmed by the Kaiser test. The cleavage and purification procedure followed the same procedure as described for the nonlabelled peptides. The molecular mass was confirmed by MALDI. (QL)6-K: expected mass for $[\mathrm{M}+\mathrm{H}]^{+}$and $[\mathrm{M}+\mathrm{Na}]^{+}: 2205.3$ and 2228.3 respectively, observed mass for $[\mathrm{M}+\mathrm{H}]^{+}$and $[\mathrm{M}+\mathrm{Na}]^{+}: 2204.9$ and 2227.9; Mel: expected $[\mathrm{M}+\mathrm{H}]^{+}:$2887.7, observed $[\mathrm{M}+\mathrm{H}]^{+}:$2887.3; $(\mathrm{QL})_{6}-\mathrm{Mel}$ : expected $[\mathrm{M}+\mathrm{H}]^{+}:$4745.8, observed $[\mathrm{M}+\mathrm{H}]^{+}:$4746.3. Rho-Mel: expected $[\mathrm{M}+\mathrm{H}]^{+}$: 3258.2, observed $[\mathrm{M}+\mathrm{H}]^{+}$: 3258.0; Rho-(QL)6-Mel: expected $[\mathrm{M}+\mathrm{H}]^{+}:$5120.1, observed $[\mathrm{M}+\mathrm{H}]^{+}: 5120.5$. 


\section{Dynamic light scattering measurement}

The light scattering measurements were made using a BI-200SM Research Goniometer System and data processed using Particle Explorer software, capable of doing angle and temperature dependent static and dynamic light scattering (DLS) evaluations, manufactured by Brookhaven Instruments Corporation, Holtsville, NY, a Nova Instruments LLC company, Wakefield, MA. Measurements were made on solutions studied in both and 10 and $25 \mathrm{~mm}$ diameter glass cells and at multiple angles, from $45^{\circ}$ to $135^{\circ}$. These solutions were equilibrated at room temperature, $23{ }^{\circ} \mathrm{C}$. Typically, the autocorrelation functions for the DLS measurements were acquired over a period of 2 or more minutes, collecting typically a million or more samples.

\section{Live and dead bacterial assay}

$400 \mu \mathrm{L}$ of bacterial suspensions (E.coli, $\left.10^{8} \mathrm{CFU} / \mathrm{mL}\right)$ was added to a confocal dish and incubated at $37^{\circ} \mathrm{C}$ for $24 \mathrm{hrs}$. Using pipette to remove bacterial suspensions and PBS buffers was used to wash away any non-adherent bacteria. $100 \mu \mathrm{L}$ of $40 \mu \mathrm{M}$ peptide solution in Tris buffer (pH 7.4, $20 \mathrm{mM}$ ) and $100 \mu \mathrm{L}$ of Mueller Hinton Broth (MHB) medium were mixed and added in the confocal dish. After incubation at $37{ }^{\circ} \mathrm{C}$ for $3 \mathrm{hrs}$, MHB medium was removed and washed extensively with PBS buffers for three times. Bacteria were stained with the live/dead bacteria assay kit solution at room temperature for $15 \mathrm{~min}$. Finally, bacteria were washed with PBS buffer for three times. Images were captured with epifluorescence and processed with ImageJ software.

\section{Live and dead mammalian cell assay}

$400 \mu \mathrm{L}$ of NIH/3T3 mouse fibroblasts was added to a confocal dish and incubated at $37^{\circ} \mathrm{C}$ for 24 hrs. Cell suspensions were removed and washed with PBS buffers for three times to remove any non-adherent cell. $180 \mu \mathrm{L}$ of fresh cell culture DMEM medium and $20 \mu \mathrm{L}$ of $200 \mu \mathrm{M}$ peptide solution in Tris buffer ( $\mathrm{pH} 7.4,20 \mathrm{mM})$ were mixed and added into the confocal dish. After incubation at $37^{\circ} \mathrm{C}$ for $3 \mathrm{hrs}$, the culture medium was removed and washed extensively with PBS buffer for three times. NIH/3T3 cells were stained with live/dead mammalian cell assay kit solution at room temperature for 20 min. Finally, cells were washed with PBS buffer 
for three times. Images were captured with epifluorescence and processed with ImageJ software.

\section{Cytotoxicity measurement}

$\mathrm{NIH} / 3 \mathrm{~T} 3$ cells were seeded onto a 96 -well plate at a density of $10^{4}$ cells/well and incubated for $24 \mathrm{hrs}$ at $37{ }^{\circ} \mathrm{C}$ in an incubator with $5 \%$ of $\mathrm{CO}_{2}$. After $24 \mathrm{hrs}$, the culture medium was removed. $10 \mu \mathrm{L}$ of peptide solution in Tris buffer $(\mathrm{pH} 7.4,20 \mathrm{mM})$ at various concentrations $(800,400$, $200,100,50,25,12.5 \mu \mathrm{M}$ ) was mixed with $90 \mu \mathrm{L}$ cell culture medium in a 96-well plate. After 24 hrs of incubation, the MTT assay was performed to quantify the cell viability by monitoring the UV absorbance at $570 \mathrm{~nm}$. The cell without incubation with peptides was used as a control. All the experiments were performed in four replicates.

\section{Statistical analysis}

The data for cytotoxicity and antimicrobial activity measurements expressed as means \pm standard deviation (SD). The statistical analysis was performed using Student's T-test and oneway analysis of variance (ANOVA) at confidence levels of $95 \%$ and above. 

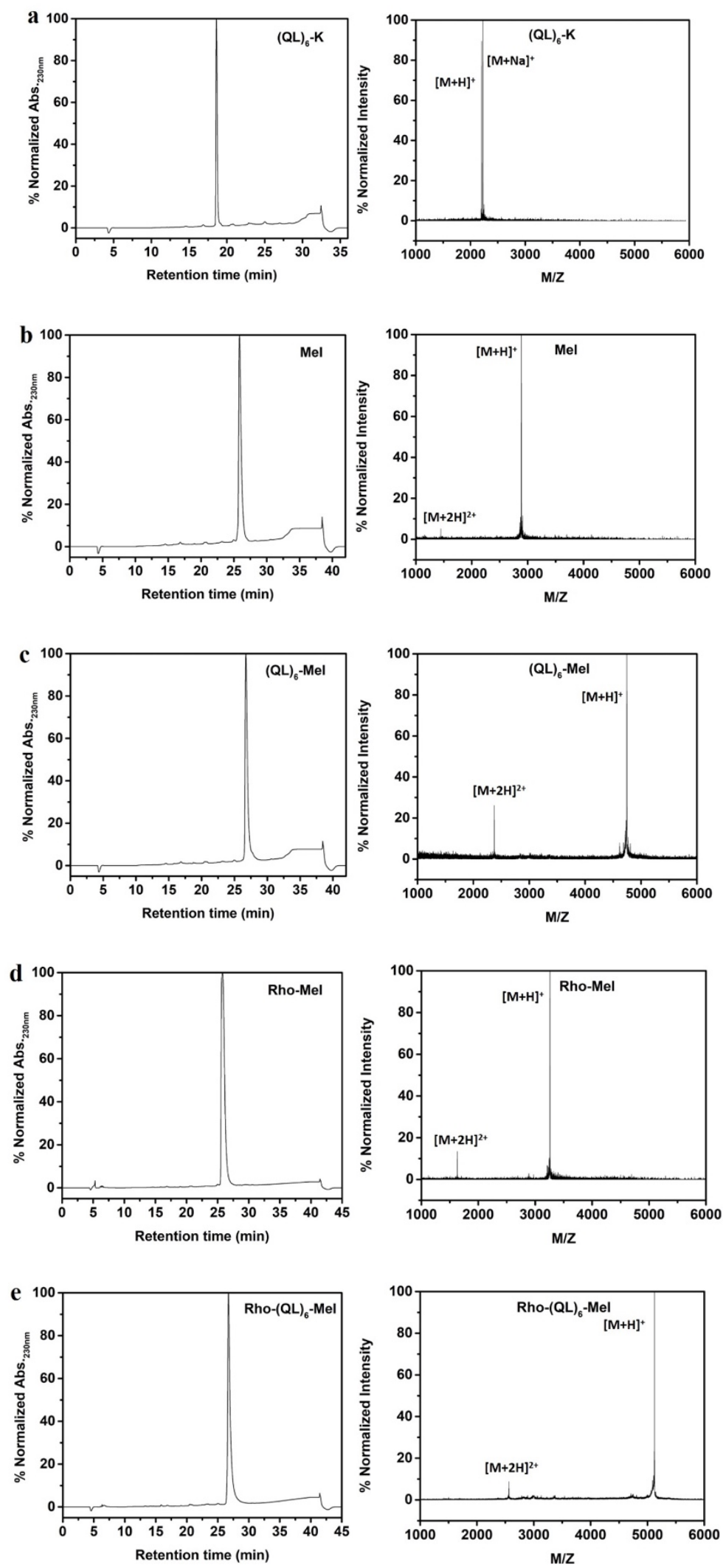

Figure S1. HPLC and MALDI spectra of (a) (QL)6-K; (b) Mel; (c) (QL)6-Mel; (d) Rho-Mel; (e) Rho-(QL)6-Mel 

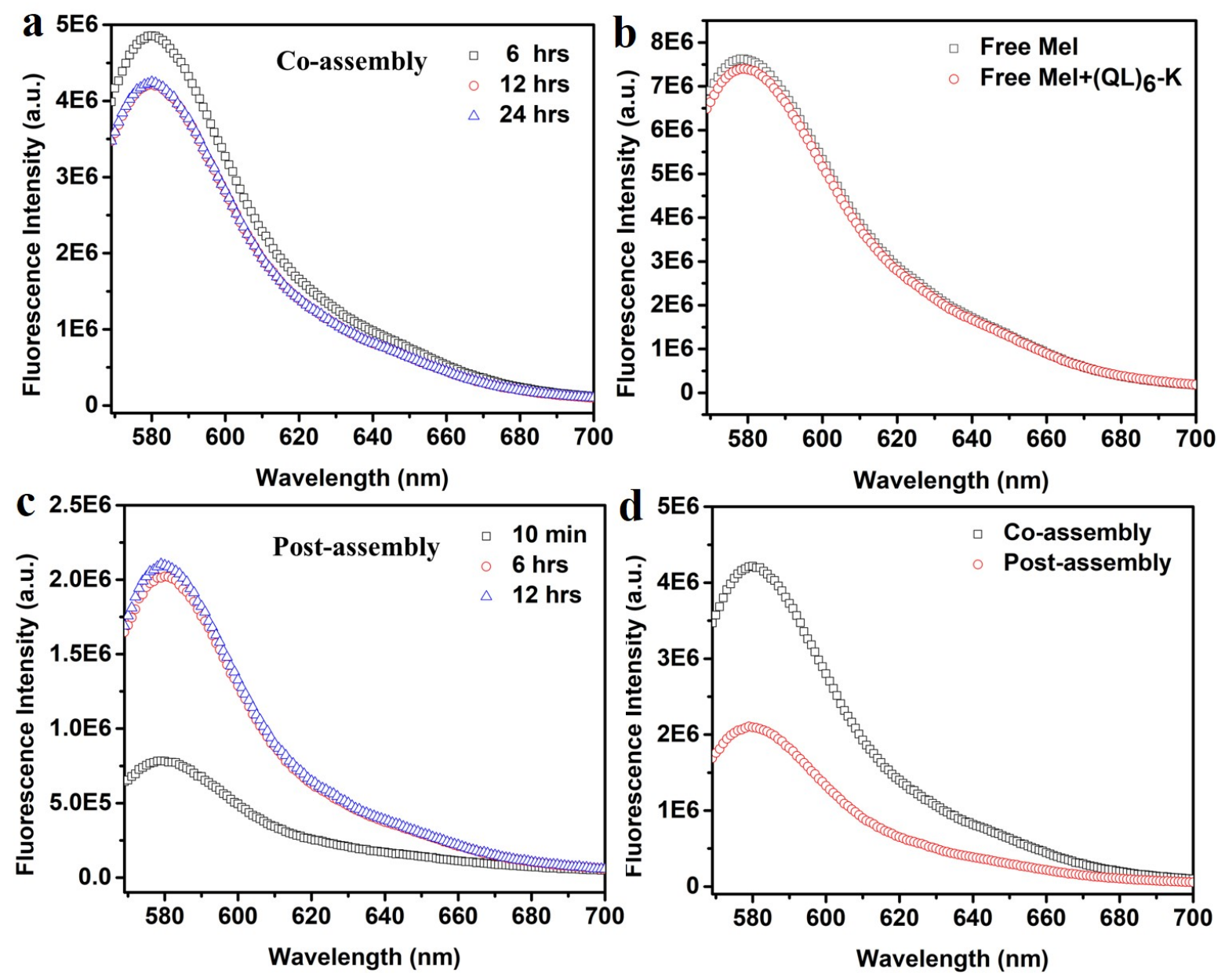

Figure S2. (a) The time-dependent fluorescence emission spectra of the Rho-labeled coassembly exhibiting a minimum change of the fluorescence intensity of the co-assembly therefore good supramolecular stability; (b) The fluorescence emission spectra of free Mel and a physical mixture of $\mathrm{Mel} /(\mathrm{QL})_{6}-\mathrm{K}$ showing comparable fluorescence intensity after $12 \mathrm{hrs}$ of incubation suggesting the lack of non-specific physical interaction between Mel and (QL)6-K nanofibers; (c) The fluorescence emission spectra of the post-assembly showing timedependent fluorescence recovery confirming the specific interaction occurs between the preformed $(\mathrm{QL})_{6}-\mathrm{Mel}$ and $(\mathrm{QL})_{6}-\mathrm{K}$ nanofibers as driven by the $\beta$-sheet forming domain of $(\mathrm{QL})_{6}$; (d) Comparison of the fluorescence emission spectra of the co-assembly versus postassembly further supports that co-assembly can be used to integrate and arrange Rho-labeled (QL) ${ }_{6}$-Mel more effectively across the entire $(\mathrm{QL})_{6}-\mathrm{K}$ nanofiber to minimize the self-quenching effect. All samples were prepared in Tris buffer $(\mathrm{pH}=7.4,20 \mathrm{mM})$ with free Rho-Mel at $1 \mu \mathrm{M}$; $\mathrm{Mel} /(\mathrm{QL})_{6}-\mathrm{K}$ physical mixture at a total concentration of $50 \mu \mathrm{M}$ consisting of $1 \mu \mathrm{M}$ of Rho$\mathrm{Mel}$; Co-assembly at a total concentration of $50 \mu \mathrm{M}$ consisting of $1 \mu \mathrm{M}$ of Rho-(QL) 6 -Mel. 


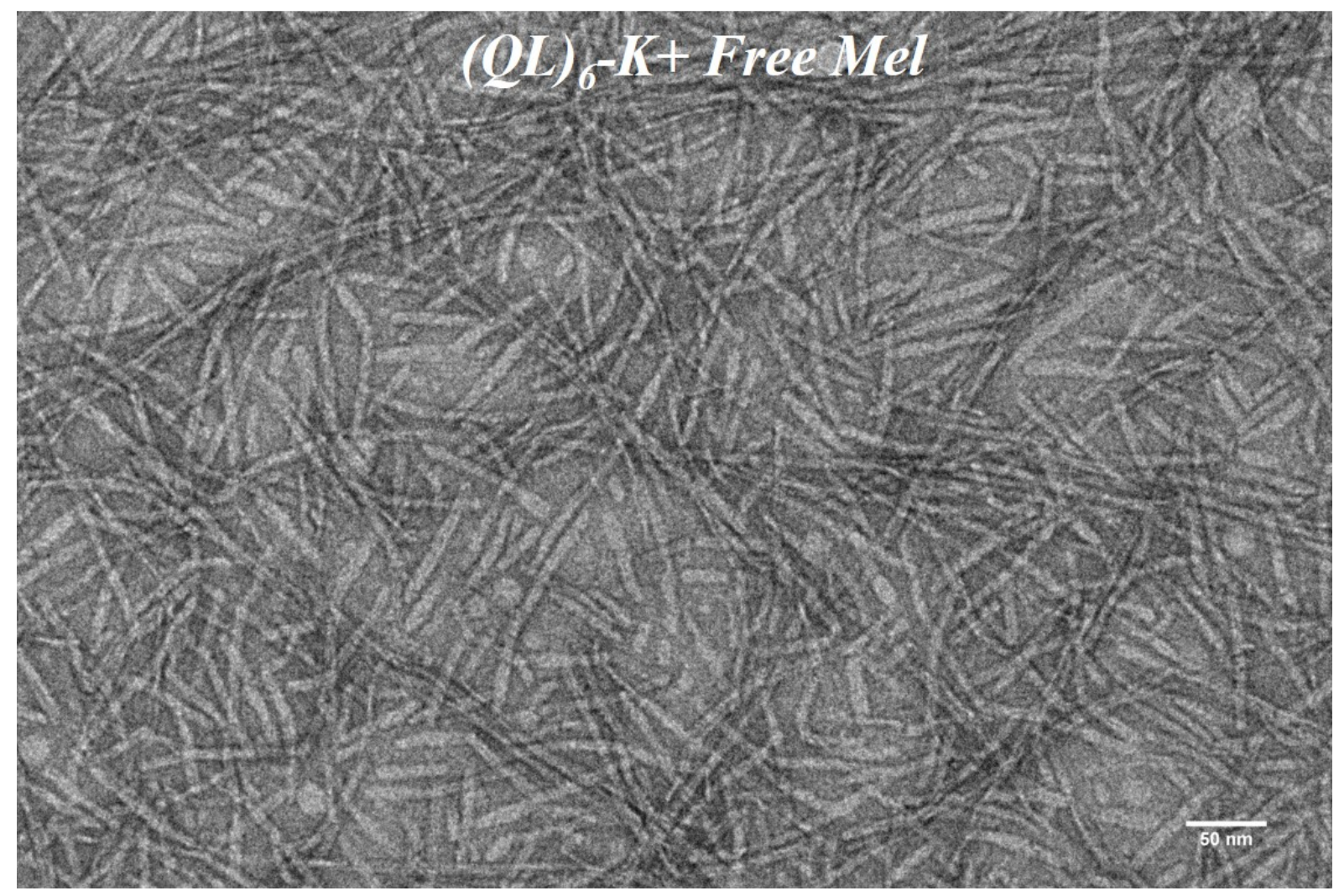

Figure S3. The TEM image of physically mixed $(\mathrm{QL})_{6}-\mathrm{K}$ with free Mel showing minimum change of the fiber morphology compared to that formed (QL) $6-\mathrm{K}$ alone, which suggests a lack of interaction between free Mel and (QL) $6-\mathrm{K}$. The peptides were prepared in Tris buffer with a total concentration at $50 \mu \mathrm{M}$ and free Mel accounts for $30 \%(15 \mu \mathrm{M})$. 

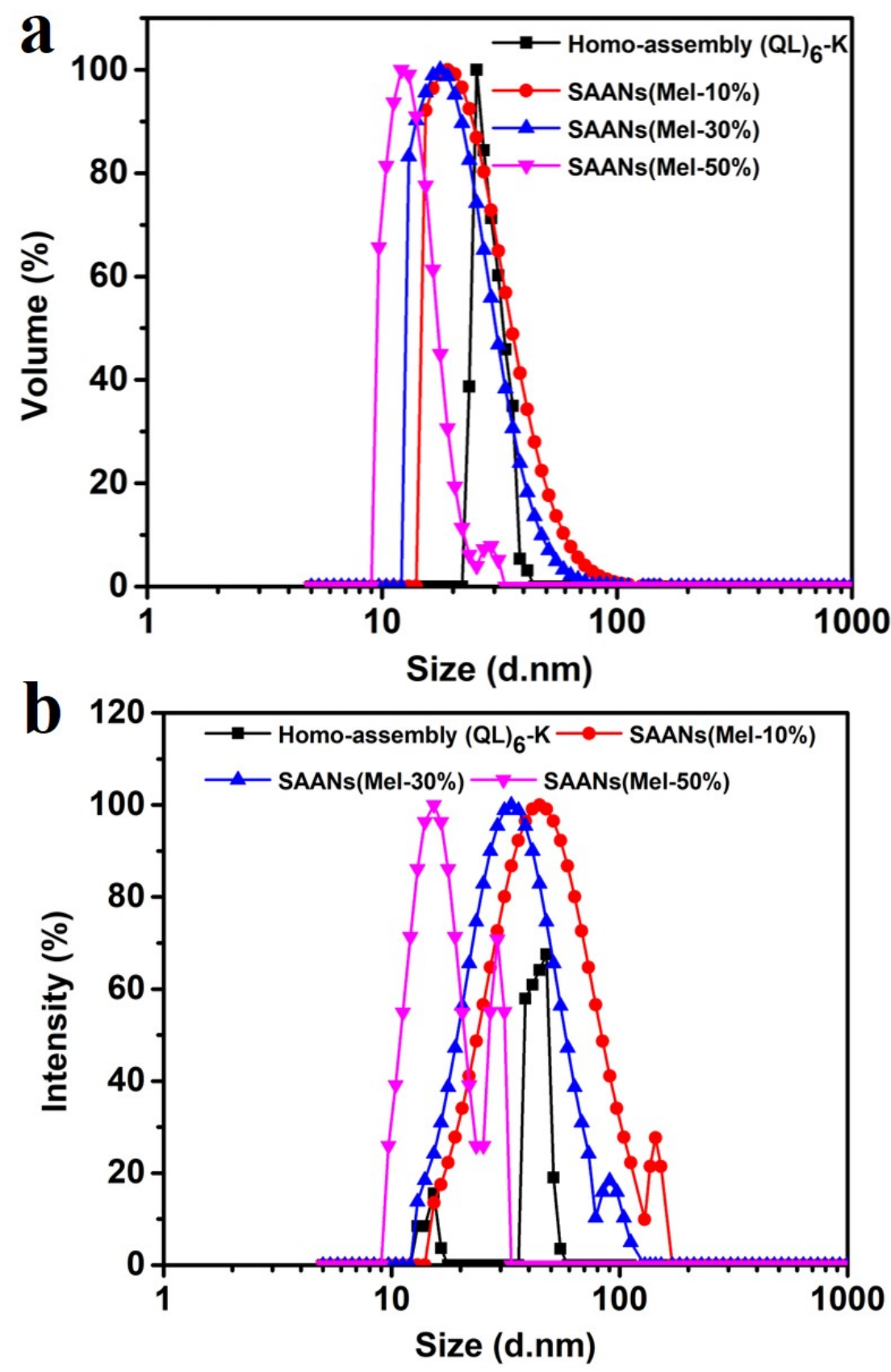

Figure S4. Hydrodynamic size characterization of different SAANs by DLS, scattering observed at an angle of $90^{\circ}$ and a temperature of $23{ }^{\circ} \mathrm{C}$. The hydrodynamic diameter distributions are weighted by: (a) particle volume and (b) particle scattering intensity. In these figures the relative fraction is based on amplitudes of scattering from the particle scattering most, a value set to 100. Notably, in both Figs. S4a and S4b, the hydrodynamic diameter of Mel-integrated SAANs decreased with increasing of Mel composition. All samples were prepared in Tris buffer $(\mathrm{pH} 7.4,20 \mathrm{mM})$ with a total peptide concentration at $10 \mu \mathrm{M}$. 

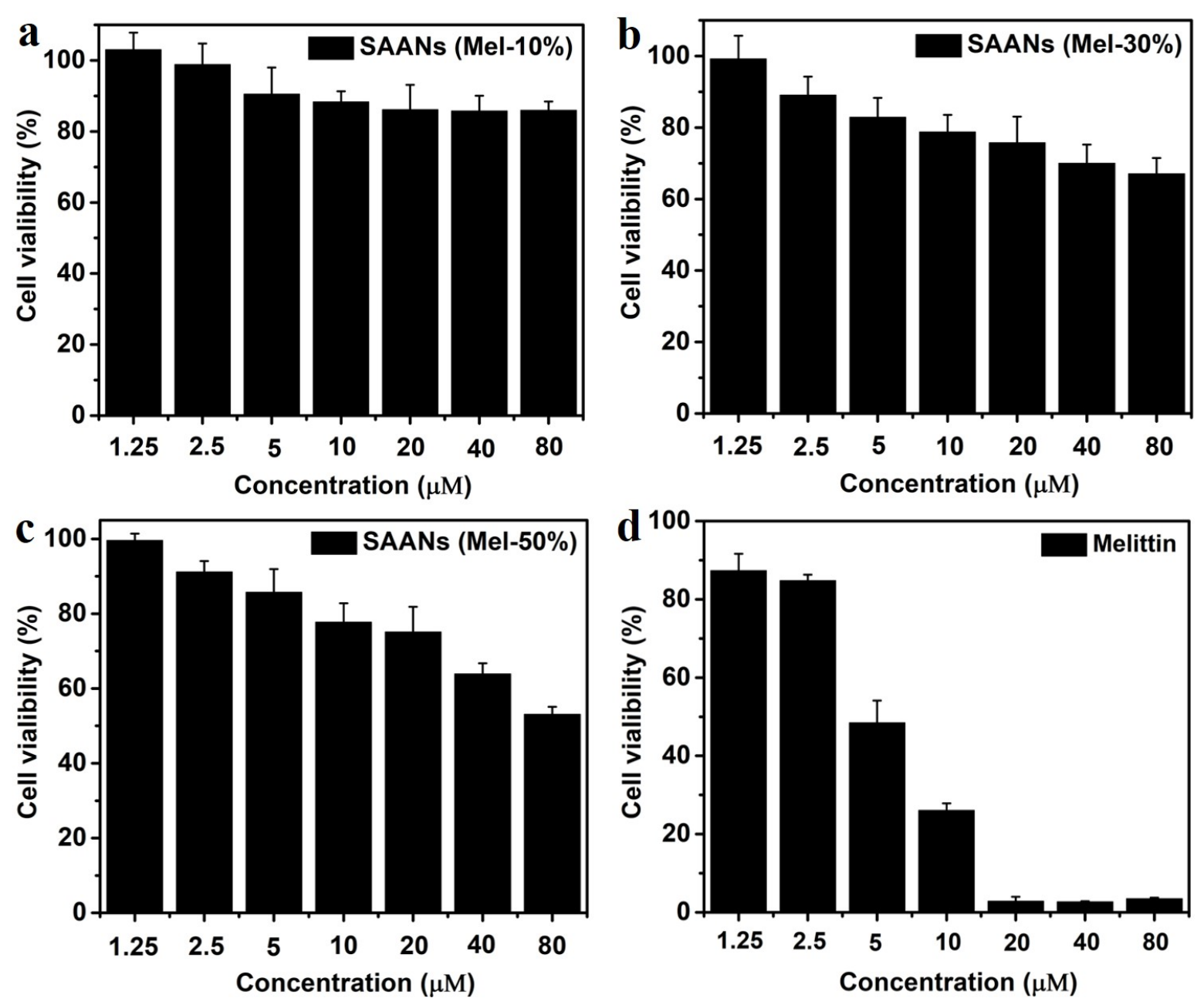

Figure S5. Additional cell viability assay of NIH/3T3 mouse fibroblasts upon incubation with different Mel-integrated SAANs, (a) SAANs (Mel-10\%), (b) SAANs (Mel-30\%) and (c) SAANs (Mel-50\%) in comparison with (d) free Mel. The assay was performed after $24 \mathrm{hrs}$ of incubation of cells with peptide samples with total peptide concentrations ranging from 1.25 $\mu \mathrm{M}$ to $80 \mu \mathrm{M}$. 


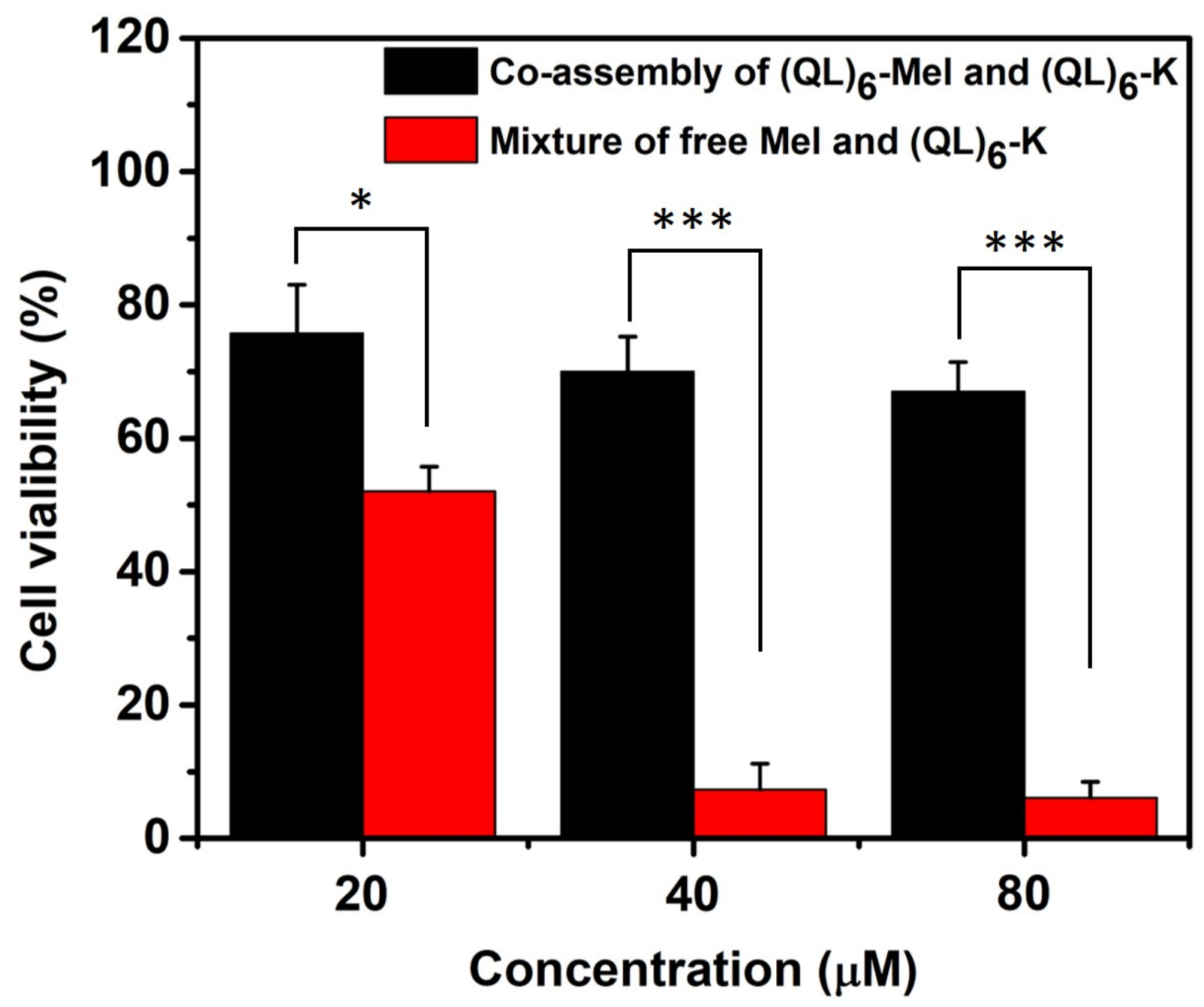

Figure S6. Cell viability assay upon $24 \mathrm{hrs}$ of incubation of peptides with NIH/3T3 mouse fibroblasts for SAANs (Mel-30\%) and physical mixtures of free Mel (30\% of total peptide concentration) and (QL) ${ }_{6}-\mathrm{K}$. The concentrations are the total peptide concentration. The results show greatly reduced cytotoxicity upon assembly. Statistic significant difference are indicated by $* \mathrm{p}<0.05, * * * \mathrm{p}<0.001$. 

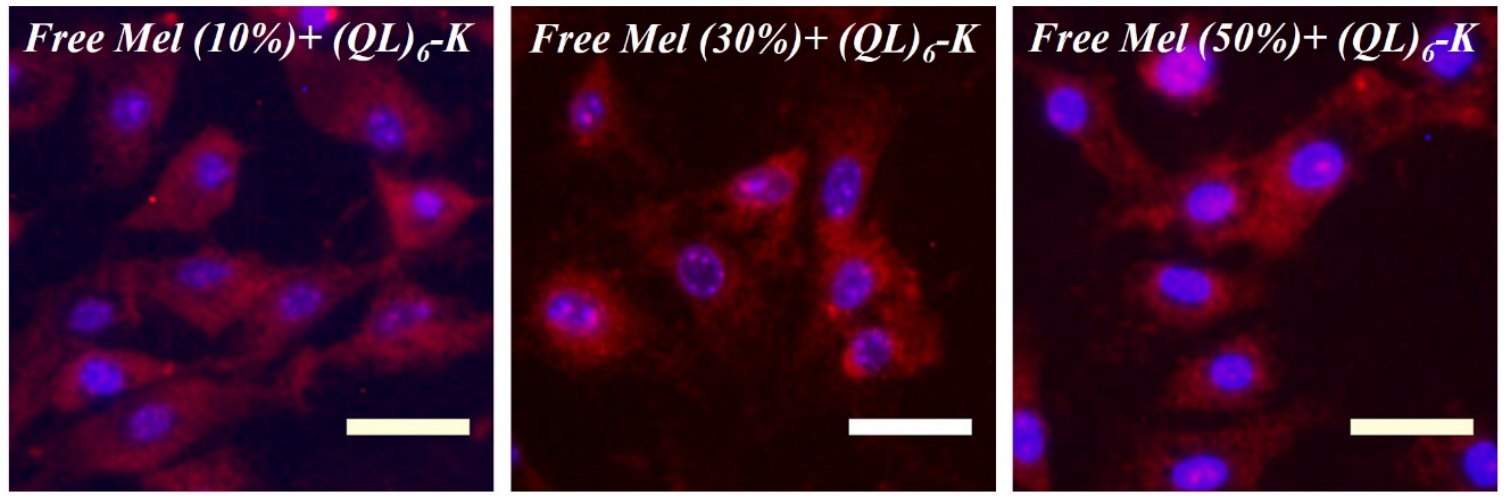

b
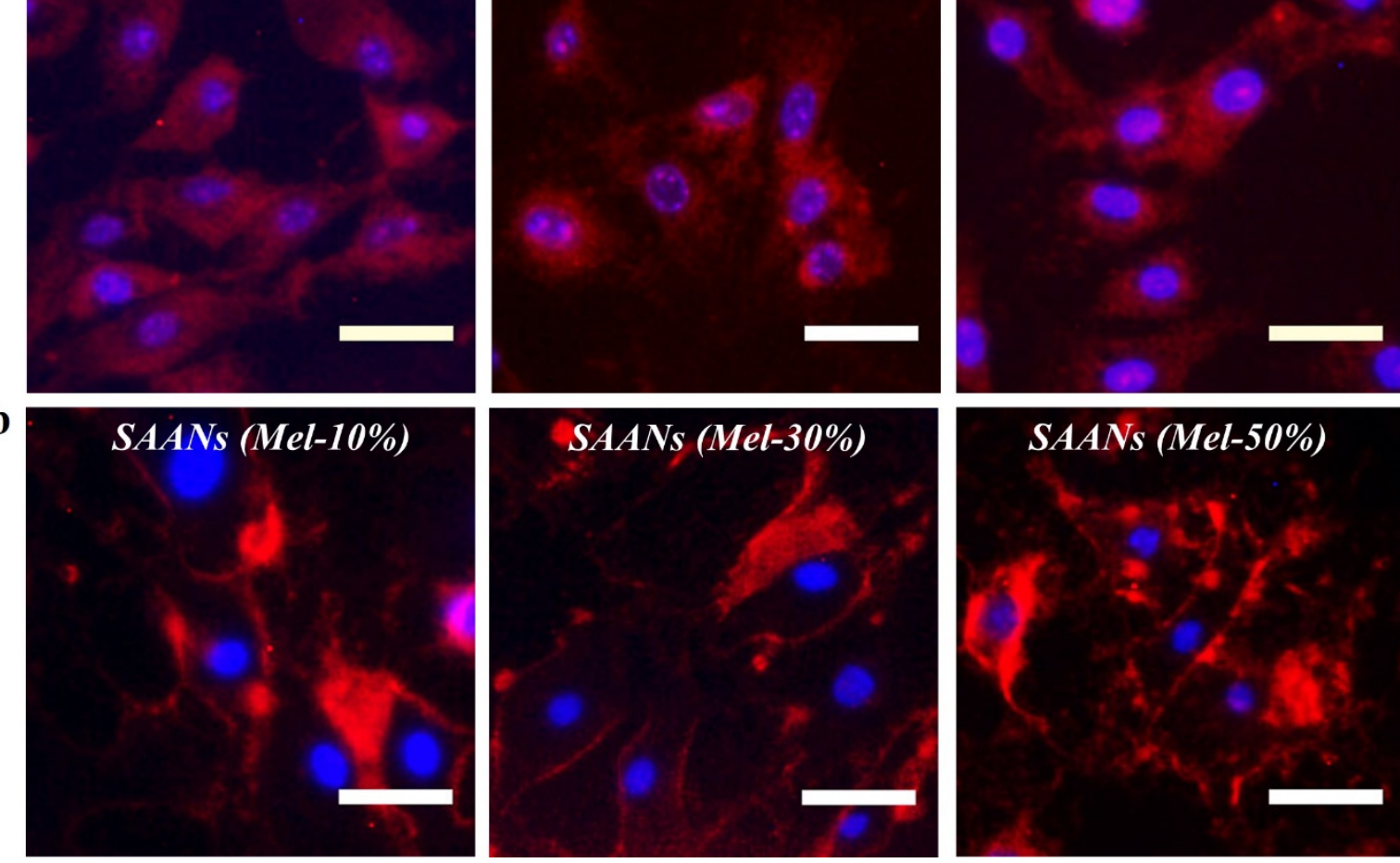

Figure S7. Fluorescence images of NIH/3T3 mouse fibroblasts treated with (a) Rho-labeled mixture of free Mel and (QL) 6 -K; (b) Mel-integrated SAANs with different Mel composition. The physical mixtures were permeabilized into cells while the co-assemblies accumulated on the membrane after $2 \mathrm{hrs}$ of incubation. The total peptide concentrations were $20 \mu \mathrm{M}$. Scale: $50 \mu \mathrm{m}$. 